\title{
Omenan viljelyn mahdollisuudet ja riskit muuttuvassa ilmastossa
}

\author{
Risto Tahvonen, Timo Kaukoranta, Arto Ylämäki
}

MTT Puutarhatuotanto,Toivonlinnantie 518,21500 Piikkiö, etunimi.sukunimi@mtt.fi

\section{Tiivistelmä}

Ilmasto muuttuu omenan viljelylle edullisemmaksi. Ratkaisevana tekijänä on kasvukauden lämpösumman lisäys tultaessa 2040-luvulle. Nykyisin viljeltävät lajikkeet edellyttävät sadon valmistumiseksi yli $5{ }^{\circ} \mathrm{C}$ :n lämpösummaa $980-1350{ }^{\circ} \mathrm{C}$-vrk. Tämän lisäksi tarvitaan puiden talveentumista varten $100-150{ }^{\circ} \mathrm{C}$-vrk lämpösumma. Kasvukauden olosuhteiden perusteella omenan ammattimainen viljelyalue, jolloin viljellään menestyksellisesti myös talvilajikkeita, voi levitä Salpausselän eteläpuolisille alueille, Kaakkois-Suomeen ja Etelä-Savon järvialueille. Ilmaston lämpeneminen mahdollistaa nykyisiä lajikkeita myöhäisempien ja paremmin säilyvien lajikkeiden viljelyn, jolloin kotimaisen omenan tarjonta voi ulottua helmi-maaliskuulle saakka.

Suomalaisen omenaviljelyn merkittävin riskitekijä on ollut talvehtiminen. Useat kovat pakkastalvet 1940 -1987 ovat käytännössä estänyt hyvälaatuisten omenalajikkeiden viljelyn Suomessa aivan edullisimpia viljelyalueita lukuun ottamatta Lounais-Suomessa ja Ahvenanmaan saaristossa. Myös tulevaisuuden ilmastossa on omenapuiden talvenkestävyys keskeinen varmuustekijä, sillä vuoden 1987 kaltaisia pakkastalvia on odotettavissa satunnaisesti.

Omenan kukinnan alku ajoittuu Suomessa touko-kesäkuun vaihteeseen. Eri lajikkeiden kukinnan alkamisen edellyttämä lämpösumma vaihtelee välillä $160-220^{\circ} \mathrm{C}$-vrk siten, että kesälajikkeet ja aikaiset syyslajikkeet kukkivat ensiksi ja talvilajikkeet viimeiseksi. Ilmaston lämpenemisen johdosta kukinta-aika tulee siirtymään vapun ja toukokuun puoliväliin rajoittuvalle ajalle. Tästä syystä kukinnan aikainen hallariski tulee säilymään tai jopa kasvamaan. Tämä edellyttää viljelyssä panostusta tehokkaaseen hallantorjuntaan. Nykyisin viljellyissä ja Piikkiön geenipankissa olevissa lajikkeissa on joitakin hallankestäviä lajikkeita, joiden käyttö parantaa viljelyvarmuutta.

Ilmaston muutos mahdollistaa omenan kotitarveviljelyn Etelä-Lappia myöten vuosisadon puoliväliin tultaessa.

Asiasanat: omena, ilmastomuutos, viljely 


\section{Johdanto}

Omenan viljelyä on Suomessa noin 650 ha:lla. Pinta-ala on EU-liittymisen jälkeen lisääntynyt noin 50 $\%: 1 l a$ (Anon. 2009). Viljelytekniikka on uudistunut viimeisten vuosikymmenien aikana täydellisesti. Ammattiviljely perustuu kasvua hillitsevien perusrunkojen käyttöön, uusiin lajikkeisiin, kastelutekniikkaan ja kasvukauden olosuhteiden (lämpösumma, kosteus ja sade) perusteella tehtäviin viljelyratkaisusuihin. Lajikkeiden valinnassa on keskitytty viime vuosikymmeninä talvenkestävyyteen, sadon laatuun ja lajikkeen kykyyn valmistua meidän kasvukautemme yli $5{ }^{\circ} \mathrm{C}: n$ lämpösummassa. Tästä syystä erityisesti mantereen alueilla on viljelyssä vain tänne testattuja uusia ja vanhoja lajikkeita (Tahvonen 2007).

Suomen omenan viljelyn päätuotantoalueilla, Lohjan seudulla, Varsinais-Suomessa ja Ahvenanmaalla oli 1960 -luvulla tehoisa lämpösumma noin $1300{ }^{\circ} \mathrm{C}$-vrk (Ilmatieteen laitos, sääaineisto), joka hädin tuskin riitti edullisimmissa viljelypaikoissa talvilajikkeiden sadon valmistukseen. Esimerkiksi Åkeron ja Lobon lämpösummavaatimukset ovat 1260 ja $1300{ }^{\circ} \mathrm{C}$-vrk (Tahvonen 2007). Ilmasto on näistä ajoista jo lämminnyt merkittävästi (IPCC 2007, Tuomenvirta 2004). MTT puutarhatutkimuksen Ilmatieteen havaintopisteessä on viimeisenä kymmenenä vuotena lämpösumma ollut noin 50 - 300 ${ }^{\circ} \mathrm{C}$-vrk korkeampi kuin 30 vuoden pitkäaikainen keskiarvo $\left(1340{ }^{\circ} \mathrm{C}\right.$-vrk) jaksolla $1971-2000$. Erityisen lämmin vuosi oli vuosi 2006, jolloin lämpösumma oli $1700{ }^{\circ} \mathrm{C}$ (Ilmatieteen laitos, sääaineisto). Kasvukauden aikaisen lämpösumman odotetaan edelleen nousevan, lumipeitteen ohenevan tai puuttuvan kokonaan ja hallajakson aikaistuvan seuraavan 40 vuoden aikana, mutta samaan aikaan huomattava vuosivaihtelu säilyy (Jylhä ym. 2004, Kaukoranta ym. 2009, Peltonen-Sainio ym. 2009).

Omenan viljelyn kriittisin vaihe on pölyttymisen onnistuminen. Aikaiset omenalajikkeet alkavat kukkia, kun lämpösummaa on kertynyt noin $160^{\circ} \mathrm{C}$-vrk, ja myöhäiset lajikkeet vastaavasti $200^{\circ} \mathrm{C}$ vrk, jolloin tyypillinen omenan kukinta-aika on ollut toukokuun loppu. Viimeisten vuosien aikana kukinta on aikaistunut heti vapun jälkeiseen aikaan. Pölyttymistä ovat vaikeuttaneet ratkaisevasti viileät ilmat ja hallat kukinta-aikana.

Suomalaisen omenaviljelyn vaikein ongelma on ollut talvehtiminen, kun lämpötilat ovat laskeneet useiksi päiviksi, jopa viikoiksi alle $-30^{\circ} \mathrm{C}$. Vain kestävimmät kotimaiset maatiaislajikkeet ja viljelyssä olleet venäläiset lajikkeet ovat selvinneet näistä talvista vaurioitta. Tästä syystä professori Jaakko Säkä aloitti 1960-luvulla laajamittaisen omenien jalostuksen, minkä tavoitteena oli ensisijaisesti talvenkestävyys ja hedelmien hyvä laatu. Tämä jalostusohjelma on tuottanut markkinoille uudet ja laadukkaat lajikkeet vaihteleviin ilmasto-oloihin. (Tahvonen 2007).

Nyt esitettävän tutkimuksen tavoitteena on luoda arvio omenan viljelyn mahdollisuuksista, kun ilmasto muuttuu 2000-luvun ensimmäisinä vuosikymmeninä.

\section{Aineisto ja menetelmät}

Tutkimus toteutettiin hyödyntämällä MTT puutarhatuotannon Piikkiössä olevia pitkäaikaisia omenaaineistoja lajikkeista ja muista omenatutkimuksista. Näiden aineistojen omenan viljelyyn soveltuvat perustulokset on julkaistu uudessa omenan viljelyn opaskirjassa (Tahvonen 2007). Uusimmat julkaisemattomat aineistot on havainnoitu pitkäaikaissäilytyksessä olevasta omenan geenipankkikokoelmasta sekä uusimmasta lajike- ja jalostusaineistosta, joissa on n. 350 lajiketta ja omaa jalostetta. Näistä omenoista, erityisesti jalosteista ja uusimmista lajikkeista Japanista, Baltian maista ja Venäjältä tehdään vuosittain menestymishavainnot. Koealueelle asetetaan kasvukausiksi sääasema (Pellonvartija, Itumic Oy) mittaamaan lämpötilaa, kosteutta ja sadetta rupienmustetta varten. Koealueen välittömässä läheisyydessä on lisäksi Ilmatieteen laitoksen sääasema. Käytetty viljelytekniikka noudattaa omenanviljelyn opaskirjan mukaista viljelyä (Tahvonen 2007).

Ilmaston muutoksesta johtuvat omenan viljelyedellytysten muutokset on esitetty Kaukoranta ym. (2009) kuvaamin menetelmin. Omenan sadon keskimääräistä valmistumista on arvioitu sadon valmistumiseen tarvittavalla yli $5{ }^{\circ} \mathrm{C}: \mathrm{n}$ lämpösummalla, johon on lisätty talveentumiseen tarvittava $150{ }^{\circ} \mathrm{C}$. Saatu tulos on kuvattu arvolla $0-1$, missä 1 kuvaa tilannetta, missä kaikkina vuosina sato valmistuu ja puut talveentuvat hyvin. Omenapuiden menestyminen on kuvattu kaudelta $1981-2010$ ja tulevasta kaudesta 2011 - 2040. Hallan aiheuttamaa kukinta-ajan vioitusriskiä on kuvattu potentiaalisilla hallapäivien lukumäärillä kukinta-aikana vuodessa. Omenapuiden menestymisarvot ja hallapäivien lukumäärät ovat alueellisia keskiarvoja, jolloin pienilmastoltaan edullisimmilla alueilla on voitu 
viljellä omenoita menestyksellisesti, vaikka alueen menestyminen ei ole laskennan perusteella hyvä tai tyydyttävä.

Tämän aineiston lisäksi tuloksissa esitetään uusia omenapuiden menestymishavaintoja 2000luvun ensimmäiseltä vuosikymmeneltä, jolloin esiintyi pitkän lämpöisen jakson jälkeen äkkinäinen pakkasjakso $-15{ }^{\circ} \mathrm{C}$ lokakuun puolivälissä v. 2002. Kasvit olivat täysin tuleentumattomia. Tähän ajanjaksoon osui myös 2 viikon jatkuva hallajakso kukinta-aikaan v. 2008, jolloin kaikki lajikkeet saivat samantasoisen "hallakäsittelyn". Lisäksi esiintyi useita lumettomia tai hyvin vähälumisia vuosia, jolloin helmi-maaliskuussa oli pitkiä $-15--25^{\circ} \mathrm{C}$ :n pakkasjaksoja.

\section{Tulokset ja tulosten tarkastelu}

Omenan viljelyn tuotantovarmuus tulee paranemaan merkittävästi. Talvilajikkeiden sato valmistuu ja puut tuleentuvat 8 vuotena kymmenestä tai paremmin Varsinais-Suomessa, Uudellamaalla ja Kaakkois-Suomessa. Vielä Tampere-Mikkeli korkeudelle asti talvilajikkeet valmistuvat ja tuleentuvat 5-7 vuotena kymmenestä, jolloin tilanne näillä alueilla on sama kuin Varsinais-Suomessa viime vuosikymmenen lopussa (kuva 1). Syyslajikkeiden menestyksellinen tuotantoalue on jo tällä hetkellä Salpausselän eteläpuolella ja Kaakkois-Suomessa. Ennustejakson loppuun mennessä luotettava tuotantoalue on Pori-Tampere-Jyväskylä-Kuopio-linjan eteläpuolella (kuva 2). Kesälajikkeiden viljely onnistuu jo nyt Vaasa-Kuopio-linjalla joka vuosi ja tulevaisuudessa potentiaalinen viljelyalue on EteläLappi-Kuusamo-alueille asti (kuva 3).

Omenan kotimaisen tuotannon perusongelma on tällä hetkellä riittämätön hyvien talvilajikkeiden tuotanto, jonka markkina-aika ilman kalliita säätöilmavarastoja olisi joulu-helmikuun välinen aika. Tästä syystä ammattimainen omenan viljely voisi hyvin laajentua Salpausselän eteläpuolisille alueille, Kaakkois-Suomeen ja Etelä-Savoon suurten vesistöjen alueille. Omenan kotitarveviljelyn mahdollisuus tulee laajenemaan merkittävästi, sillä useat uudet hyvälaatuiset kesä- ja syyslajikkeet ovat talvenkestävyydeltään perinteisten lajikkeiden veroisia (Tahvonen 2007).

Suomessa ovat kukinnan aikaiset hallat olleet harvinaisempia kuin eteläisimmissä maissa. Ilmastoennusteiden mukaan näyttäisi kukinnan aikaisten hallapäivien lukuisuus hieman lisääntyvän siirryttäessä kohti tämän vuosisadan puoliväliä. Riski on kaikkein suurin aikaisilla kesälajikkeilla aivan Etelä-Suomessa, jossa omenoiden täyskukinta tulee olemaan toukokuun alussa (kuva 4). Tästä syystä ammattiviljelyksillä on investoitava tehokkaisiin hallantorjuntavälineisiin. Vuonna 2008 oli Piikkiössä kaksi viikkoa kestävä yhtenäinen hallajakso omenan kukinnan aikaan. Tällöin kaikki lajikkeet saivat kukinta-aikaeroista huolimatta samankaltaisen ankaran hallan. Noin 350 lajikkeen ja jalosteen joukossa oli noin 15 lajiketta ja jalostetta, jotka antoivat tyydyttävän tai jopa hyvän sadon kukinta-aikaisesta hallasta huolimatta. Yhteistä näille lajikkeille ja jalosteille oli, että ne olivat peräisin joko Venäjältä ja Kanadasta tai niiden risteytysvanhempana oli käytetty jotain "hallankestävää" lajiketta. Tämä yksittäisen vuoden havaintoaineisto viittaa siihen, että lajikevalinnalla ja jalostuksella voidaan kehittää hallaa sietäviä lajikkeita.

Viimeisen vuosikymmenen aikana talvet ovat olleet hyvin vähälumisia ja jopa täysin lumettomia. Kireimmät pakkaset ovat olleet helmi-maaliskuussa, $20-25{ }^{\circ} \mathrm{C}$ ja satunnaisina päivinä lähellä $30{ }^{\circ} \mathrm{C}$. Vuoden 2002 loppukesä ja alkusyksy lokakuulle asti oli hyvin lämmin, jolloin kasvien lehdet säilyivät täysin vihreinä äkkinäiseen lokakuun $-15{ }^{\circ} \mathrm{C}: n$ pakkaseen asti. Näillä "poikkeusoloilla" ei tuntunut olevan merkitystä seuraavan vuoden kasvuun ja kukintaan. Näyttääkin ilmeiseltä, aikaisempien vuosien perustyö ja lajikevalinta on tuonut meidän käyttöön riittävän talvenkestävät lajikkeet tulevien vuosien varalle. Mikäli tulevina vuosina esiintyy satunnaisesti vuoden 1987 kaltaisia pakkastalvia, meillä jo viljelyssä olevat uudet ulkomaiset lajikkeet, joiden talvenkestävyys on samaa luokkaa tai heikompi kuin 'Lobo'-lajikkeen kestävyys, tulevat kärsimään merkittäviä vaurioita. Vuoden 1987 pakkasissa menetettiin kokonaisia tarhoja aivan eteläisintä Suomea myöten. 


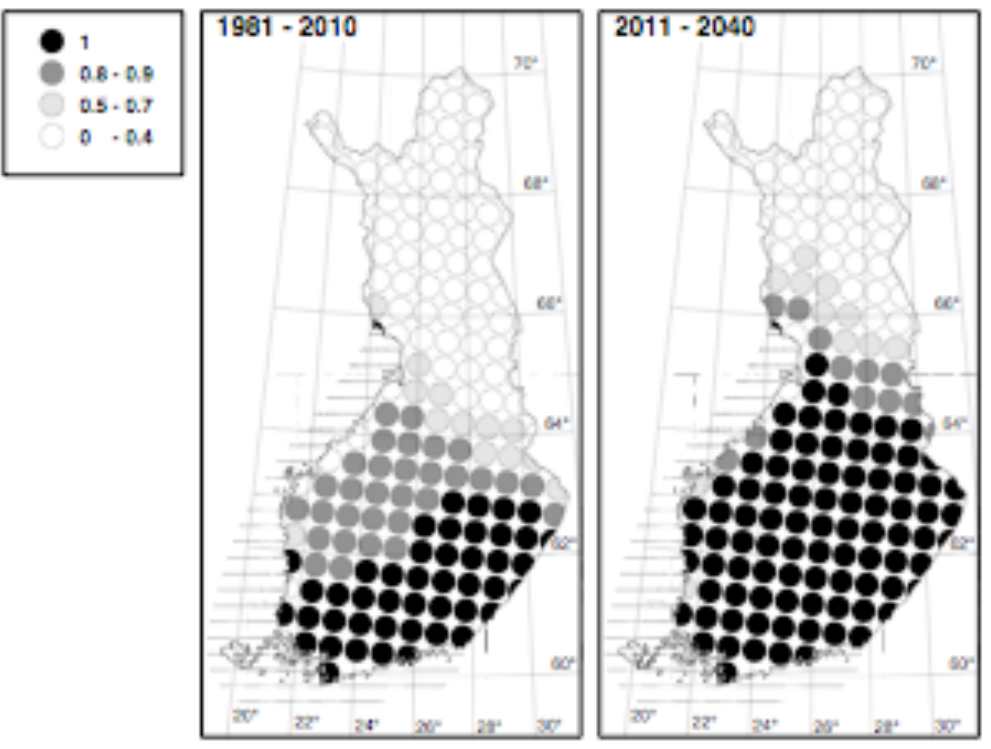

Kuva 1. Kesälajikkeen 'Pirja' sadon valmistuminen ja talveentuminen vuosina 1981-2010 ja 2011-2040. Lajikkeen sadon valmistumisen lämpösummavaatimus $970^{\circ} \mathrm{C}$.
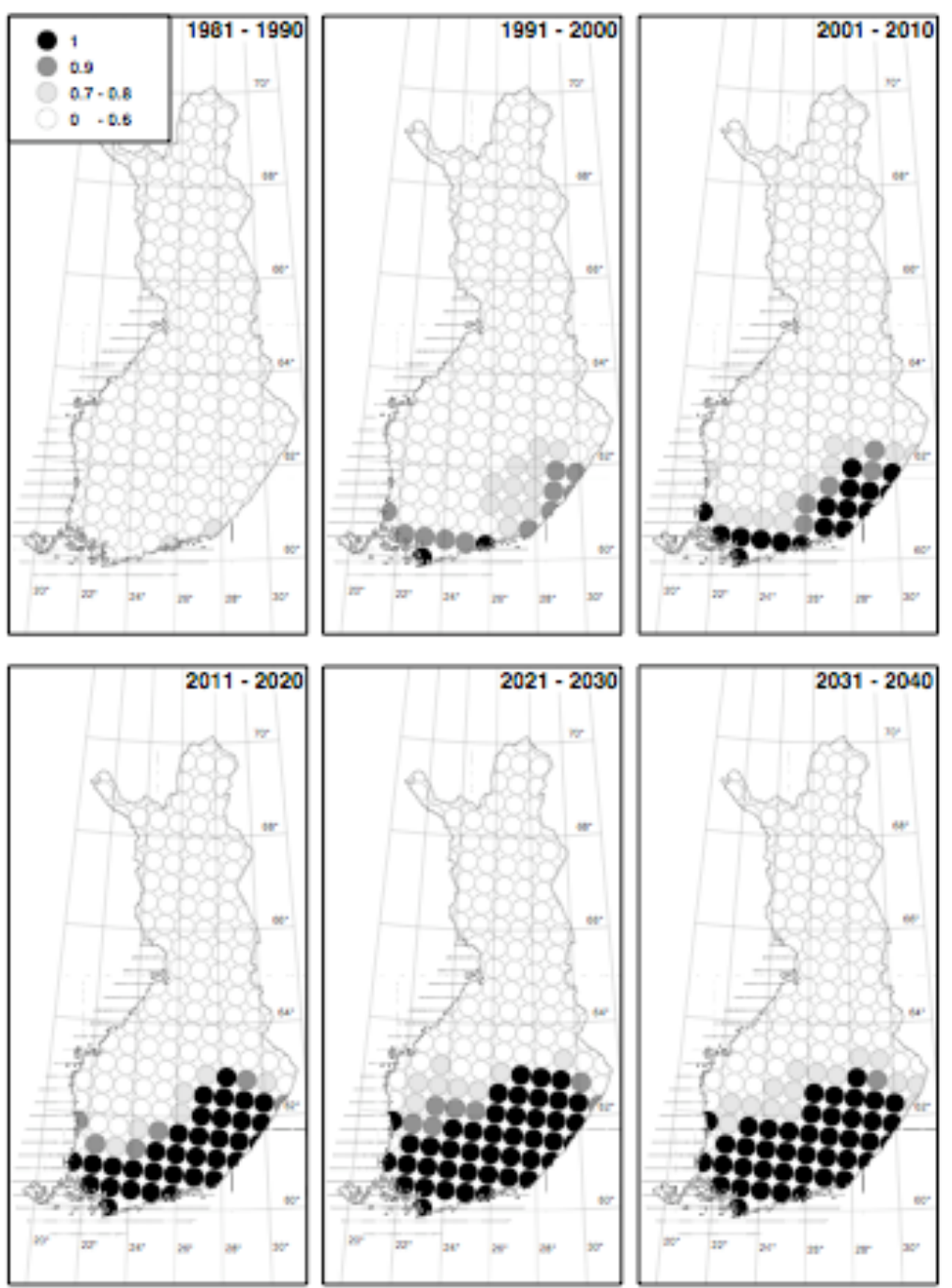

Kuva 2. Syyslajikkeen 'Melba' sadon valmistuminen ja talveentuminen vuosina 1981 - 2040. Lajikkeen sadon valmistumisen lämpösummavaatimus $1190{ }^{\circ} \mathrm{C}$. 


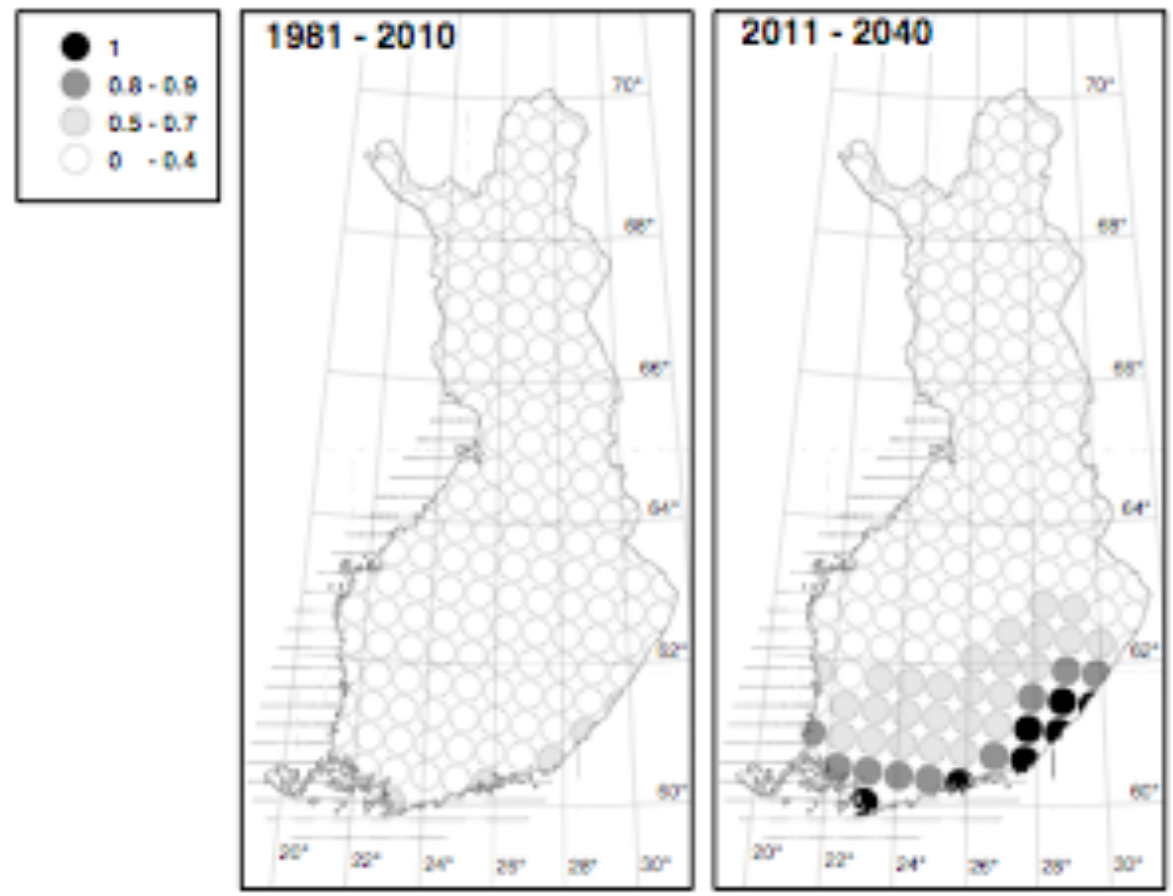

Kuva 3. Talvilajikkeen 'Lobo' sadon valmistuminen ja talveentuminen vuosina 1981-2010 ja 2011-2040. Lajikkeen sadon valmistumisen lämpösummavaatimus $1300{ }^{\circ} \mathrm{C}$.
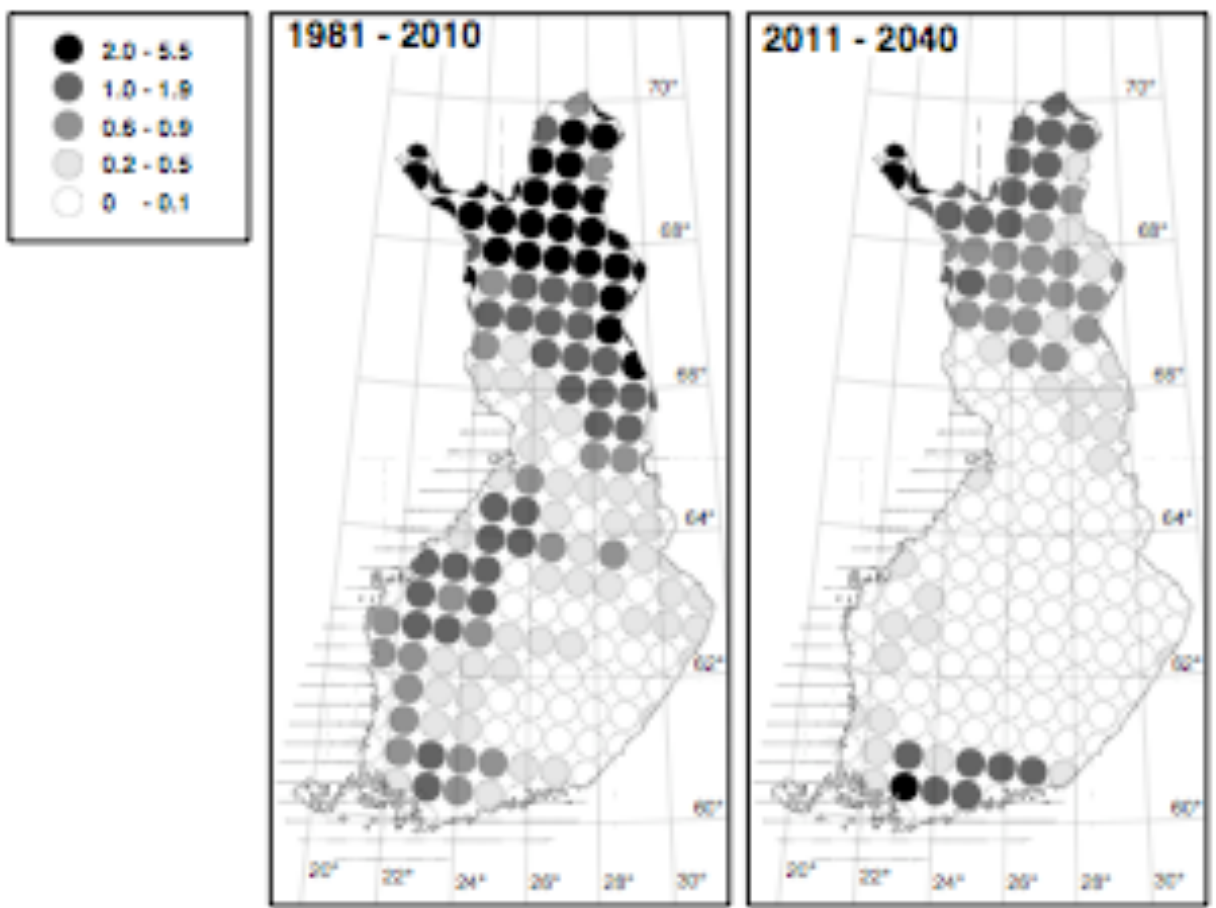

Kuva 4. Potentiaalisten hallapäivien lukumäärä vuodessa 'Pirja'-lajikkeen kukinta-aikana. 


\section{Johtopäätökset}

Ilmastomuutos vuosisadan alkupuoliskolla mahdollistaa ammattimaisen omenaviljelyn laajentumisen käytännössä nykyistä II-viljelyvyöhyketta myöten sekä tietyin lajikevarauksin III-vyöhykkeen pienenilmastollisesti parhaimmille alueille. Kasvukauden pidentymisen johdosta viljelyyn voidaan ottaa uusia talvilajikkeita, joiden markkinointiaika ulottuu helmikuulle asti ilman säätöilmavarastoja. Kukinnan aikainen hallariski tulee hieman lisääntymään, jolloin viljelmien kannattaa varautua tehokkaaseen hallantorjuntaan. Lajikkeiden valinnassa kannattaa pitäytyä talvenkestäviksi todettuihin, mutta hyvälaatuisiin lajikkeisiin, sillä vuoden 1987 kaltaiset pakkastalvet ovat edelleen mahdollisia erityisesti sisämaassa.

\section{Kirjallisuus}

Anon. 2009. Puutarhanumerot, tilastoja puutarha-alalta. 28 p. Puutarhaliitto. Helsinki.

IPCC. 2007. Climate Change 2007: The Physical Science Basis. Contribution of Working Group I to the Fourth Assessment Report of the Intergovernmental Panel on Climate Change. (eds.) Solomon, S., Qin, D., Manning, M., Chen, Z., Marquis, M., Averyt, K.B., Tignor, M. \& Miller, H.L. Cambridge University Press, Cambridge, UK and New York, NY, USA, 996 p.

Jylhä, K., Tuomenvirta, H. \& Ruosteenoja, K. 2004. Climate change projections for Finland during the $21 \mathrm{st}$ century. Boreal Environment Research 9: 127-152.

Kaukoranta, T., Tahvonen, R. \& Ylämäki, A. 2009. Climatic potential and risks for apple growing by 2040. Agricultural and Food Science, in press.

Peltonen-Sainio, P., Jauhiainen, L., Hakala, K. \& Ojanen, H. 2009. Climate change and prolongation of growing season: changes in regional potential for field crop production in Finland. Agricultural and Food Science, in press.

Tahvonen, R. 2007. Omenan viljely. 248 p. Puutarhaliitto. Helsinki.

Tuomenvirta, H. 2004. Reliable estimation of climatic variations in Finland. Diss. University of Helsinki. 79 p. Finnish Meteorological Institute Contributions No. 43. 